\title{
12)

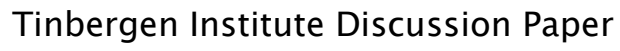 \\ An Analysis of the Effects of the Severance Payment Reform on Credit to Italian SMEs
}

\author{
Riccardo Calcagno $1,3,4$ \\ Roman Kraeuss/1,5 \\ Chiara Monticone 2,4
}

\footnotetext{
1 VU University Amsterdam;

2 University of Torino;

3 Tinbergen Institute;

${ }^{4} \mathrm{CeRP}$;

${ }_{5}$ Center for Financial Studies, Frankfurt.
} 


\section{Tinbergen Institute}

The Tinbergen Institute is the institute for economic research of the Erasmus Universiteit Rotterdam, Universiteit van Amsterdam, and Vrije Universiteit Amsterdam.

Tinbergen Institute Amsterdam

Roetersstraat 31

1018 WB Amsterdam

The Netherlands

Tel.: +31(0)205513500

Fax: $+31(0) 205513555$

Tinbergen Institute Rotterdam

Burg. Oudlaan 50

3062 PA Rotterdam

The Netherlands

Tel.: + $31(0) 104088900$

Fax: $+31(0) 104089031$

Most TI discussion papers can be downloaded at http://www.tinbergen.nl. 


\title{
An Analysis of the Effects of the Severance Payment Reform on Credit to Italian SMEs*
}

\author{
Riccardo Calcagno
}

November 4, 2008

\begin{abstract}
We study the effects of the reform of the system of severance payments (TFR) of Italian employees on the cost and the access to credit for small and medium-size enterprises (SMEs). The most direct consequence of the reform is to reduce in the long run the amount of liquid assets available to Italian firms. We argue that this reform, implemented in July 2007, will reduce the aggregate investment by SMEs in a more than proportional way, since it will restrict the access to credit for some of them (Holmstrom and Tirole, 1997). However, we also predict that the reform will not increase the cost of intermediated finance, coeteris paribus. In order to assess the effects of the reform on the investment of SMEs and on the cost of bank loans, we also estimate the future outflows of TFR funds due to the reform.
\end{abstract}

Keywords: severance indemnities; moral hazard; credit constraints; SMEs

JEL Codes: G31, G32, G38

\footnotetext{
*This research has been supported by the Center for Research on Pensions and Welfare Policies (CeRP), at Collegio Carlo Alberto, Torino. We also want to acknowledge CERIS for providing us the access to AIDA, Stefan Arping, Onorato Castellino, Elsa Fornero and Giovanna Nicodano for their useful comments. We owe many thanks to Simone Ceccarelli (Covip), Angelo Pace (Bank of Italy), Alessandro Cappellini, Vilma Marchese and Martin Marchese (Intesa-San Paolo) for their assistance in the collection of data, as well as to the participants to seminars at Collegio Carlo Alberto (Turin), VU University Amsterdam, the 2007 Conference on Macroeconomics and International Finance by the University of Crete.

${ }^{\dagger}$ VU University Amsterdam, Tinbergen Institute and CeRP. Corresponding author, email: rcalcagno@feweb.vu.nl

${ }^{\ddagger}$ VU University Amsterdam and Center for Financial Studies, Frankfurt.

${ }^{\S}$ CeRP and University of Torino.
} 


\section{Introduction}

Berger and Udell (1998) observe that small, private businesses are "acutely informationally opaque" and argue that this is a major impediment for them to access the public capital markets. Small firms are forced to rely mostly on internal cash resources and on intermediated finance, because intermediaries have some advantages on direct lending through the debt markets. They can offer SMEs specific contracts that alleviate the acute adverse selection problem (Bester (1985)) and they can monitor firms activity reducing moral hazard (Diamond (1984)).

A recent reform of the system of severance indemnities in Italy is likely to affect the amount of liquid assets of Italian SMEs, hence their main source of internal finance. This law, included in the Financial Budget Law for 2007, allows employees to choose from July 2007 on whether they want the future flows of their severance indemnity fund ("Trattamento di Fine Rapporto", TFR) to be invested in pension funds, instead of being kept in the firm, as it was previously done. Before the reform, a quota approximately equal to one month pay was retained by the firm and paid to the worker at the moment he/she would leave (voluntarily or not) his current employer ${ }^{1}$. From the point of view of the firm, these funds were very similar to long-term corporate debt, although with two major differences. The funds were being backed by a State insurance scheme in case of insolvence of the firm, and by receiving a remuneration determined by the Italian $\mathrm{law}^{2}$. Since the rate of return paid on the TFR was lower than the risk-free rate of Treasury bond in most of the years (at least before the introduction of the Euro), the TFR flows traditionally provided cheap finance for Italian firms.

The reform of July 2007 allows workers to transfer their future TFR flows in a pension fund ${ }^{3}$. Thus, Italian SMEs will lose (part) of this cheap and liquid liability, in a proportion related to the amount of workers who decide to invest their TFR outside the firm. The objective of this paper is to determine the long-run effects of this reform on the access and the cost of credit for small- and medium-sized firms.

\footnotetext{
${ }^{1}$ Every year, the employer must set aside in the TFR a quota equal to 1/13,5 (7.41annual salary. Actually, only $6.91 \%$ is accumulated each year, as $0.5 \%$ is paid to National Institute for Social Security Payments (INPS).

${ }^{2}$ The TFR is capitalized annually at a rate equal to $1.5 \%$ plus $\frac{3}{4}$ of the inflation rate measured in the previous year by the Italian National Statistical Office (ISTAT).

${ }^{3}$ More precisely, the law distinguishes between firms with less than 50 employees, and those with 50 employees or more: for those working in the former who choose not to invest their TFR in pension funds, it will remain within the firm; for those who work in larger firms, the same choice will imply that the TFR indemnities are automatically deposited within INPS.
} 
There is a quite large empirical evidence that the debt capacity of Italian SMEs is positively correlated with the dimension of the assets they can pledge as collateral. Sapienza (1997) disentangles the determinants of the demand and the supply of credit and concludes that loans supply is significantly correlated with assets tangibility. Guiso (2003) shows that size is a major determinant of the probability of success in obtaining as much bank finance as needed: firms with less than approximately 30 employees are twice less likely to have financial debt than bigger firms, and this probability is strongly and positively correlated with the quota of tangible assets over total assets. From these observations, he concludes that "firms' ability to pledge collateral strengthens their capacity to borrow, in particular when bank-firm relationships are not well established".

These empirical findings justify the use of the model of credit rationing proposed by Holmstrom and Tirole (1997) (HT in the following) in order to study the impact of the reform of severance payments on SMEs. Since it is well documented that Italian SMEs have almost no access to public debt, we use a modified version of HT assuming that the supply of capital to firms is due only to financial intermediaries (in particular banks) who typically perform an activity of costly monitoring firms' decisions. We show that in the long run the lower amount of liquid assets available to each firm makes the credit constraints for the smaller firms more severe, reducing their total investment; in turn, this decreases their demand of external finance, and the interest rate. The main intuition of this result is that since debt capacity is increasing in the amount of liquid assets invested by the firm itself, reducing the latter also reduces the former, so that SMEs will be able to make less investments on aggregate. As an extension of the HT framework, we consider the case in which banks can optimally choose their monitoring level, and we conclude that in this extended model version both the effects produced in the long run on the investment level and the interest rate are exacerbated. Our theoretical framework allows us to quantify the reduction in investment SMEs will suffer as a function of the predicted outflow of severance indemnity. Our main theoretical prediction is that in the long run the flow of new investments will decrease by more than proportionally to the TFR outflow. For our empirical analysis we have collected data from the Bank of Italy about the total credit granted to Italian firms, divided by class of the total amount of credit each client has received. Assuming that most of the SMEs receive a total annual credit which is less than 125,000 euros, we obtain an upper bound of their total bank borrowing. From ISTAT data showing the distribution of private sector employees and earnings across firms' size (defined by the number of employees) we recover the annual flow of TFR in 2007. Based on assumptions on the macroeconomic development of 
employment and wages, we then project TFR flows for the period 2008-2010 and assess the magnitude of TFR funds that Italian firms would lose as a result of the reform.

Finally, we use data from Guiso (2003) to obtain the average leverage of SMEs towards financial institutions. Our simulations predict that the decrease of SMEs investment due to the reform will be equal to $130-147 \%$ of the outflow of TFR in the long run. Our theoretical model also forecasts that in equilibrium the loan rate will not increase in the long run; empirically, we forecast it may slightly decrease - coeteris paribus - for an amount inversely proportional to the elasticity of the supply of bank capital.

Our results suggest that in order to reduce the negative impact of the reform on SMEs investment, the Italian government should not subsidize the cost of future bank loans to firms (as it is doing now), but instead should protect the access to credit of firms who are loosing a quota of their liquid funds.

The remainder of this paper is organized as follows. Section 2 presents the basic theoretical framework for the analysis, which is a simplified version of HT (1997), while section 3 discusses the effects of the policy change predicted by the model. Section 4 presents the data and our estimates for the future outflows of TFR, together with a quantitative assessment of the main effects of the reform on the future investment and the loan rate. Section 5 concludes.

\section{The basic model}

Our theoretical framework for the analysis of the effects of the reform of the Italian severance payment system is a simplified version of the model in Holmstrom and Tirole (1997). In our version of the model there are two sets of agents: (small) firms and financial intermediaries. They operate on two periods: in the first period a financial contract between each single firm and a competitive intermediary (a bank in the following) is signed, and firms invest; in the second period the returns of investment are realized and are distributed. Each firm has an initial amount of capital $A_{0}$, representing the market value of all assets that can be pledged as a collateral to the financial contract (a loan in the following). The distribution of assets across firms is described by the c.d.f. $F(A)$, and the aggregate amount of firm capital is denoted by $K_{f}=\int A d F(A)$. All banks are identical in any relevant respect for the analysis.

Each firm is endowed with the same investment projects: a good project $G$ and a bad project $W$. The firm can undertake any of them paying an initial amount $I>A_{0}$, which represents the scale of the project. The firm 
with own internal capital $A_{0}$ needs then to borrow (at least) $I-A_{0}$ from the bank in order to undertake the investment at level $I$. Investing $I$ in the good project generates at $t=2$ a verifiable return, equal either to 0 (with probability $1-p_{H}$ ) or to $R(I)$ (with probability $p_{H}$ ), while the investment $I$ in the bad project pays 0 with probability $1-p_{L}$ and $R(I)$ with probability $p_{L}$, with $p_{L}<p_{H}$.

In each firm a risk-neutral entrepreneur selects his preferred project. Moral hazard between the entrepreneur and the investor is formalized as in HT: for any unit of investment in the bad project, the entrepreneur enjoys private benefits $B$. The choice of the good project by the entrepreneur reduces his private benefits to zero.

Following Holmstrom and Tirole, the gross rate of return on bank loans is denoted by $\beta$. On the public capital markets the risk-free rate is normalized to zero. As in HT, we assume that $\beta \geq 1$ in order to make economically profitable for banks to invest in the SMEs' projects. All individuals are riskneutral, and due to portfolio optimization, the aggregate supply of credit to SMEs is (weakly) increasing with $\beta$ : the higher $\beta$, the more restricted is the set of alternative projects in the economy which provide at least the same expected return as the ones undertaken by SMEs. Thus, the higher $\beta$, the more capital banks will be willing to invest in SMEs' projects.

Only the good project dominates the investment in public capital markets while the bad project has a negative NPV:

$$
p_{H} R(I)-I>0>p_{L} R(I)+B I-I
$$

Given (1), a necessary condition for the firm getting external finance is the entrepreneur chooses the good project:

$$
p_{H} R^{f}(I) \geq p_{L} R^{f}(I)+B I
$$

where $R^{f}(I)^{4}$ is the share of the project returns paid to the firm. Under (2) each SME chooses the amount of internal assets $A \leq A_{0}$ to invest, knowing that the expected return for the bank is bounded by the quota of the proceeds that is paid to the firm $R^{f}$, in order to let the entrepreneur choose project $G$. Finally, we assume that the total return of the project in case of success is linear in the initial investment, $R(I)=R I$. Under these assumptions, it is obvious that the firm will invest all its internal funds in the project, $A=A_{0}$, but it will never borrow more than it needs to implement a given investment level $I$. Indeed, the internal rate of return of an investment in

\footnotetext{
${ }^{4}$ From now on, for easiness of notation, we will drop the functional form $R^{f}(I)$ to just $R^{f}$.
} 
the good project for a firm is higher than $\beta^{5}$ and, for any fixed $I$, the firm pays a gross return of $\beta \geq 1$ on external funds (while the opportunity cost of internal funds is equal to 1 ).

The decision problem of the risk-neutral entrepreneur is then simpl given as:

$$
\begin{aligned}
& \\
& \max _{I} p_{H} R^{f} \\
\text { s.t. } \quad p_{H}\left(R I-R^{f}\right)= & \beta\left(I-A_{0}\right) \\
p_{H} R^{f} \geq & p_{L} R^{f}+B I
\end{aligned}
$$

where the first constraint ensures that the bank earns a gross return of $\beta$ on its investment $I-A_{0}$ and the second constraint ensures that the entrepreneur chooses the good project (incentive constraint).

Substituting for (3) we can rewrite the incentive constraint (4) as

$$
A_{0} \geq I\left(1-\frac{p_{H}}{\beta}\left(R-\frac{B}{\Delta p}\right)\right)
$$

.We assume that the expression within brackets is positive which is equivalent to specify that the NPV of the good project at a cost of capital of $\beta$ is positive. We can then rewrite the problem as

$$
\begin{aligned}
& \max _{I} p_{H} R I-\beta\left(I-A_{0}\right) \\
\text { s.t. } \quad I \leq & \frac{A_{0}}{1-\frac{p_{H}}{\beta}\left(R-\frac{B}{\Delta p}\right)}
\end{aligned}
$$

Since we have assumed that the internal rate of return of a good project is higher than $\beta$, firms invest the highest possible $I$ given the initial liquid assets equal to $A_{0}$ :

$$
I=\frac{A_{0}}{1-\frac{p_{H}}{\beta}\left(R-\frac{B}{\Delta p}\right)}
$$

A form of "investment multiplier" of internal cash is at work here: each unit invested by the firm allows to attract more than one unit of external

\footnotetext{
${ }^{5}$ Investing in a good project, a firm earns

$$
\begin{aligned}
p_{H} R^{f} & =p_{H} R I-\beta(I-A)=\left(p_{H} R-\beta\right) I+\beta A \\
& =\left(p_{H} R-\beta\right) I+\beta A_{0}
\end{aligned}
$$

which is higher than what the firm would get investing all her liquid assets $A_{0}$ at rate $\beta$.
} 
capital to invest in the good project. Indeed, $A_{0}$ increases the total investment $I$ by $1 /\left[1-\frac{p_{H}}{\beta}\left(R-\frac{B}{\Delta p}\right)\right]>1$. The final payoff is split between $R^{f}$, which goes to the firm, and $R^{b}$, paid to the bank, in such a way that it is possible to remunerate the bank capital exactly at the gross discount rate $\beta$, and to let the firm earn a higher rate on its initial investment $A_{0}$.

To find the equilibrium on the market for intermediated capital, we solve for the rate $\beta^{*}$ that equalizes demand and supply of bank capital. The aggregate demand of credit is given by

$$
D(\beta)=\int\left(I-A_{0}\right) d F\left(A_{0}\right)=\left(\frac{1}{1-\frac{p_{H}}{\beta}\left(R-\frac{B}{\Delta p}\right)}-1\right) \int A_{0} d F\left(A_{0}\right)
$$

while the supply of bank capital is exogenously given and equal to $K_{b}(\beta)$, where $K_{b}^{\prime}=\partial K_{b}(\beta) / \partial \beta>0$. The aggregate demand of intermediated capital is monotone decreasing in $\beta^{6}$.

Let $K_{f}=\int A_{0} d F\left(A_{0}\right)$ be the aggregate internal funds of firms. The equilibrium on the (intermediated) capital market is:

$$
\begin{aligned}
\left(\frac{1}{1-\frac{p_{H}}{\beta}\left(R-\frac{B}{\Delta p}\right)}-1\right) K_{f} & =K_{b}(\beta) \\
E\left(R^{b}\right)\left(K_{f}+K_{b}(\beta)\right) & =\beta K^{b}(\beta)
\end{aligned}
$$

where we denote for simplicity $p_{H}(R-B / \Delta p)=E\left(R^{b}\right)$

The market clearing is obtained varying the return $\beta$ (hence the aggregate supply of capital $K_{b}(\beta)$ as well), while $K_{f}$ is fixed. One can interpret the equilibrium condition as follows: if $\beta$ is "too" high, the supply of capital banks are willing to invest in SMEs is higher than the demand; reducing $\beta$ increases the maximum investment $I$ a firm with initial liquid assets $A_{0}$ can sustain, by $(5), ;$ thus in turn increases the demand $D(\beta)$, and reduces the supply $K_{b}(\beta)$ until the equilibrium is reached. Notice finally that the aggregate level of investment, $K_{f}+K_{b}(\beta)$, depends only on the aggregate level of firm capital $K_{f}$, since $K_{b}(\beta)$ adjusts to guarantee the equilibrium on the market.

$$
{ }^{6} \text { Denoting } p_{H}\left(R-\frac{B}{\Delta p}\right)=E\left(R^{b}\right) \text { we have: } \frac{\partial\left(\frac{K_{f}}{1-\frac{E\left(R^{b}\right)}{\beta}} \frac{E\left(R^{b}\right)}{\beta \beta}\right)}{\partial \beta}=\frac{E\left(R^{b}\right) K_{f}}{E\left(R^{b}\right)-\beta} \frac{1}{\beta-E\left(R^{b}\right)}<0 .
$$




\section{The effects of the reform: the model pre- dictions}

The reform approved by the Italian Parliament allows each employee in the private sector to invest his future flows of severance indemnities (TFR), which the firm was managing up to 2007 as its own liabilities, in pension fund schemes. Thus, if we assume that the status quo is stationary in the sense that the inflows of severance payments in every period is equal to the outflows, the reform is going to reduce the inflow without affecting the outflow of TFR. Each firm will then suffer a reduction in the amount of liquid assets. In terms of the model presented above, the most direct consequence of this reform is a decline of $A_{0}$ (with respect to the case of no reform) from July 2007 on. The key question of interest is then how such a decrease in all firms' internal funds affects the equilibrium cost of capital, demand of credit and investment.

From (5) it is clear that a reduction of one unit in $A_{0}$ decreases $I$ by more than one unit. As a consequence, less bank capital can be attracted due to the binding participation constraint of the bank: $I^{b}=p_{H}\left(R-\frac{B}{\Delta p}\right) I / \beta$. This in turn reduces the aggregate demand of intermediated capital. We can show that as a consequence of this "multiplier" effect, the reduction of aggregate investment at equilibrium is higher than the reduction of the aggregate amount of liquid assets $K_{f}$.

Proposition 1 If all firms' internal liquid funds $A_{0}$ marginally decrease, causing a decrease of the aggregate internal funds $K_{f}$, then the cost of bank capital for the firms will decrease as well as the aggregate investment in the firms (good) projects. Moreover, the latter will reduce more than proportionally than $K_{f}$ :

$$
\begin{aligned}
\frac{d \beta}{d K_{f}} & =\frac{E\left(R^{b}\right)}{K_{b}^{*}+\left(\beta^{*}-E\left(R^{b}\right)\right) K_{b}^{\prime}\left(\beta^{*}\right)} \geq 0 \\
\frac{d I}{d K_{f}} & >1
\end{aligned}
$$

Proof: A decrease in each firm $A_{0}$ is going to reduce the firm investment, see (5). However, the aggregate reduction in $K_{f}$ will also have an effect on the equilibrium cost of capital $\beta$, by $(7)^{7}$. Let us rewrite equation (5) as:

$$
I=(1+\phi(\beta)) A_{0}
$$

${ }^{7}$ The comparative statics result described in HT for $\frac{\partial\left(K_{b}+K_{f}\right)}{\partial K_{f}}$ holds only if one considers $\frac{\partial \beta^{*}}{\partial K_{f}}=0$. 
where $\phi(\beta)=\frac{E R^{b} / \beta}{1-E R^{b} / \beta}>0$ iff $\beta>E R^{b}$. Aggregating (10) across firms one obtains

$$
\begin{aligned}
K_{b}+K_{f} & =(1+\phi(\beta)) K_{f} \\
K_{b} & =\phi(\beta) K_{f}
\end{aligned}
$$

Differentiating the equilibrium condition (7) w.r.to $K_{f}$ we obtain:

$$
\begin{aligned}
\frac{d \beta}{d K_{f}} K_{b}\left(\beta\left(K_{f}\right)\right)+\beta \frac{d K_{b}}{d K_{f}} & =E R^{b}\left(1+\frac{d K_{b}}{d K_{f}}\right) \\
\frac{\partial \beta}{\partial K_{f}} K_{b}(\beta)+\beta\left(\frac{\partial K_{b}}{\partial \beta} \frac{\partial \beta}{\partial K_{f}}\right) & =E R^{b}\left(1+\frac{\partial K_{b}}{\partial \beta} \frac{\partial \beta}{\partial K_{f}}\right) \\
\frac{\partial \beta}{\partial K_{f}}\left(K_{b}+\frac{\partial K_{b}}{\partial \beta}\left(\beta-E R^{b}\right)\right) & =E R^{b} \\
\frac{\partial \beta}{\partial K_{f}} & =\frac{E R^{b}}{K_{b}+K_{b}^{\prime}\left(\beta-E R^{b}\right)} \geq 0
\end{aligned}
$$

We now move to compute explicitly the change in aggregate investment, $1+\frac{d K_{b}}{d K_{f}}$ due to the variation $d K_{f}$. From $K_{b}=\phi\left(\beta\left(K_{f}\right)\right) K_{f}$ one obtains:

$$
\begin{aligned}
\frac{d K_{b}}{d K_{f}} & =\frac{\partial K_{b}}{\partial \beta} \frac{\partial \beta}{\partial K_{f}}+\frac{\partial K_{b}}{\partial K_{f}} \\
& =K_{f} \phi^{\prime}(\beta) \frac{\partial \beta}{\partial K_{f}}+\phi(\beta)
\end{aligned}
$$

where $\phi^{\prime}(\beta)=-\frac{E R^{b}}{\left(\beta-E R^{b}\right)^{2}}<0$. Substituting for $\phi^{\prime}(\beta)$ and $\phi(\beta)$ into the previous expression leads to:

$$
\begin{aligned}
\frac{d K_{b}}{d K_{f}} & =K_{f} \frac{\partial \beta}{\partial K_{f}}\left(-\frac{E R^{b}}{\left(\beta-E R^{b}\right)^{2}}\right)+\frac{E R^{b} / \beta}{1-E R^{b} / \beta} \\
\frac{d K_{f}+d K_{b}}{d K_{f}} & =K_{f}\left(1-\frac{\partial \beta}{\partial K_{f}} \frac{E R^{b}}{\left(\beta-E R^{b}\right)^{2}}\right)+\frac{E R^{b} / \beta}{1-E R^{b} / \beta} \\
& =\frac{E R^{b}}{\beta-E R^{b}}-\frac{E R^{b}}{\left(\beta-E R^{b}\right)^{2}} K_{f} \frac{\partial \beta}{\partial K_{f}}+K_{f} \\
& =\phi(\beta)-\phi(\beta) K_{f} \frac{1}{\beta-E R^{b}} \frac{\partial \beta}{\partial K_{f}}+K_{f}
\end{aligned}
$$

and substituting for $\frac{\partial \beta}{\partial K_{f}}$ results in: 


$$
\begin{aligned}
\frac{d K_{f}+d K_{b}}{d K_{f}} & =\phi(\beta)\left(1-K_{f} \frac{1}{\beta-E R^{b}} \frac{E R^{b}}{K_{b}+K_{b}^{\prime}\left(\beta-E R^{b}\right)}\right)+K_{f} \\
& =\phi(\beta)\left(1-\frac{E R^{b}}{\beta-E R^{b}} \frac{K_{f}}{K_{b}+K_{b}^{\prime}\left(\beta-E R^{b}\right)}\right)+K_{f} \\
& =\phi(\beta)\left(1-\phi(\beta) \frac{K_{f}}{K_{b}+K_{b}^{\prime}\left(\beta-E R^{b}\right)}\right)+K_{f} \\
& =\phi(\beta)\left(1-\phi(\beta)\left(\frac{K_{f}}{K_{b}}-\delta\right)\right)+K_{f} \\
& =\phi(\beta)\left(1-\phi(\beta) \frac{K_{f}}{K_{b}}+\delta \phi(\beta)\right)+K_{f} \\
& =\delta \phi^{2}(\beta)+K_{f}>K_{f}
\end{aligned}
$$

where $\delta=\frac{K_{f}}{K_{b}}-\frac{K_{f}}{K_{b}+K_{b}^{\prime}\left(\beta-E R^{b}\right)}>0$.

We can make three important observations. First, the proof of the proposition shows our main difference with the theoretical findings in HT. Their comparative statics result for $\frac{\partial\left(K_{b}+K_{f}\right)}{\partial K_{f}}$ holds only if one considers $\frac{\partial \beta^{*}}{\partial K_{f}}=0$. In proposition 1 we explicitely consider this indirect effect on the equilibrium loan rate.

Secondly, notice that at a firm level the same result as proposition 1 holds for the firm investment only if all firms suffer the same proportional loss in $A_{0}$. In our setup, however, it is not crucial whether the reduction in $A_{0}$ is different across firms, since every firm has the same production function. Thus, for the aggregate level of investment what matters is only the total amount of TFR funds that is transferred from the firms ${ }^{8}$.

Finally, to estimate relations (8)-(9), we will use the fact that in the model $E\left(R^{b}\right) / \beta^{*}=I^{b} / I$, while the elasticity of the supply of capital to SMEs $K_{b}^{\prime} /\left(K_{b}^{*} / \beta^{*}\right)$ must be calibrated on real data.

We now check whether the role of banks as firms monitors (Diamond (1984)) may alter the predictions obtained before. For simplicity we consider monitoring as essential for receiving bank finance (because SMEs do not have access to uninformed finance in our model), but in their role of delegated monitors, banks also suffer of a moral hazard problem towards the depositors (Diamond (1984); Chiesa (2001)). Thus, in our model, contrarily to HT, the choice of monitoring by the bank is endogenous.

\footnotetext{
${ }^{8}$ When the technology is the same for all firms affected by the reform and it has constant returns to scale, it is not important which firm actually loses most due to the exit of TFR funds and which one is affected less. They all have, in a way, the "same" production function.
} 
We restrict our analysis to an exclusive bank-firm relationship ${ }^{9}$. We first show that the monitoring intensity of banks increases with the ratio of own capital to the total invested capital (as in Chiesa (2001), Carletti (2004), Carletti et al. (2005), among others). To illustrate this point, let us write the profit function of a representative bank as:

$$
\Pi^{b a n k}=E\left[\max \left\{\widetilde{R}^{b} I-r_{D} D ; 0\right\}\right]-\frac{c I}{2} m^{2}
$$

where

$$
\widetilde{R}^{b}=\left\{\begin{array}{c}
R-\frac{B}{\Delta p} \text { with proba. } p_{H}(m) \\
0 \quad \text { with proba. } 1-p_{H}(m)
\end{array}\right.
$$

given that, to provide the entrepreneur with the right incentives, the maximum payoff obtained by the bank is $R-(B / \Delta p)$ for each unit invested. The probability of success of the good project is increasing in the level of monitoring effort by the bank. We denote with $r_{D}$ the rate of return paid on deposits, and with $D$ the amount of deposits raised by the bank. The cost of monitoring activity is linear in the dimension of the project (the investment I) and convex in the monitoring intensity $m^{10}$.

The rationale of this formalization is that by performing a high monitoring activity the bank can improve the expected cash flow of the project (increasing the probability of success).

Rewriting (11) gives

$$
\begin{aligned}
\Pi^{\text {bank }} & =p_{H}(m)\left(R^{b} I-\left(r_{D}-S\right) D\right)-\frac{c I}{2} m^{2} \\
& =p_{H}(m)\left(R^{b}\left(A_{0}+E+D\right)-\left(r_{D}-S\right) D\right)-\frac{c I}{2} m^{2}
\end{aligned}
$$

where $S=\left(1-p_{H}(m)\right) r_{D}$ represents the per -unit expected shortfall on the deposit contract, $E$ is the bank own equity capital, and $c$ is the unit monitoring cost for the bank. Solving for the optimal monitoring intensity

\footnotetext{
${ }^{9}$ We assume here that SMEs will not change the number of bank relationships following the reform. Hellwig (1991), Rajan (1992) and Petersen and Rajan (1995) show that a unique bank relationship helps the access to credit, but it can be more expensive in the long run (a "hold up" problem). However, Detragiache et al. (1997) find that Italian firms typically maintain multiple relations with banks. In principle, we cannot exclude then that, if the firms access to credit will decrease in the future, some of the smallest firms will react by restricting themselves to a unique relation with a bank.

${ }^{10}$ We choose such a formalization for the costs of monitoring since without moral hazard between bank and depositors the optimal monitoring intensity would be independent of $I$.
} 
gives:

$$
\begin{gathered}
\max _{m} \Pi^{\text {bank }} \\
m^{*}=\frac{\Delta p}{c}\left(R^{b}-r_{D} \frac{D}{I}\right)
\end{gathered}
$$

which is decreasing in $D / I$ because of the moral hazard towards depositors. Since the deposit rate is set before monitoring is decided, the bank always has an incentive to increase her profit by increasing the expected shortfall, thus reducing monitoring ex-post. The higher the ratio of external capital, $D / I$, the lower the incentive to provide monitoring.

The next step verifies that proposition 1 holds also in this new setup. Turning to the equilibrium condition (7), the lower monitoring activity affects the term $E\left(R^{b}(m)\right)$ that is now equal to $p_{H}(m) R^{b}-(c / 2) m^{2}$. This term is increasing in $m$ since by f.o.c. of (12), $\Delta R^{b}-c m^{*}=-\frac{\partial S}{\partial m} D>0$. Thus a reduction on $m$, caused by the lower $A_{0}$, reduces in turn $E\left(R^{b}(m)\right)$ causing an even stronger decrease in $K_{b}(\beta)$ at equilibrium ${ }^{11}$. The effect on aggregate investment described in proposition 1 is then exacerbated when we allow banks to monitor the firms activity, choosing their optimal monitoring intensity.

\section{An estimate of the capital outflows due to the reform}

In order to make predictions about the change of the aggregate credit granted by banks and about the loan rate obtained by SMEs, we have to quantitatively determine two elements exogenous to our theoretical analysis. First,

${ }^{11}$ More formally, we can re-write the aggregated equilibrium condition as:

$$
\beta K_{b}(\beta)=E\left(R_{b}(m)\right)\left(K_{f}+K_{b}\right)
$$

and differentiate by $d K_{f}$. We obtain

$$
\begin{aligned}
\frac{d \beta}{d K_{f}}\left(K_{b}(\beta)+K_{b}^{\prime}(\beta)\left(\beta-E\left(R^{b}(m)\right)\right)\right) & =E\left(R^{b}(m)\right)+\frac{\partial E\left(R_{b}(m)\right)}{\partial m} \frac{\partial m}{\partial K_{f}}\left(K_{f}+K_{b}\right) \\
\frac{d \beta}{d K_{f}} & =\frac{E\left(R^{b}(m)\right)+\frac{\partial E\left(R^{b}(m)\right)}{\partial m} \frac{\partial m}{\partial K_{f}}\left(K_{f}+K_{b}\right)}{K_{b}(\beta)+K_{b}^{\prime}(\beta)\left(\beta-E\left(R^{b}(m)\right)\right)} \\
& >\frac{E\left(R^{b}(m)\right)}{K_{b}(\beta)+K_{b}^{\prime}(\beta)\left(\beta-E\left(R^{b}(m)\right)\right)}
\end{aligned}
$$

for any given level of $m$, since monitor intensity $m$ increases when total investment $K_{f}+K_{b}$ is higher (due to the fact that the ratio $D / I$ reduces for higher $I$ ) and since $\frac{\partial E\left(R^{b}(m)\right)}{\partial m}>0$. 
we have to predict the outflow of funds from SMEs due to the reform. Second, we need to assess the reaction of the bank credit to SMEs following a collateral squeeze. Here we concentrate on the first aspect.

The TFR consists in a fraction of gross earnings set aside by the employ$\mathrm{ers}^{12}$ and paid back to workers when their working relationship ends (for any reason, including retirement). The amount set aside every year sums up to the already existing stock which is capitalized at a given rate ${ }^{13}$.

The severance pay reform, firstly announced and approved in 2004 but modified afterwards within the Budget Law of 2007, does not concern the TFR stock already accumulated within the firms, but only its future flows. More precisely, from July 2007 on workers have to decide whether to invest their current and future TFR flows in private pension funds or not. If they do not make an explicit choice, their TFR flows will be automatically diverted into pre-specified pension funds, according to a mechanism where no choice is equivalent to a tacit consent. In case they explicitly state that they $d o$ not want to join any pension fund, their TFR will either be accumulated to INPS (if they work in firms with $50+$ employees ${ }^{14}$ ), or it will remain at the firm's disposal (for firms with less than 50 employees).

Even though the reform has been implemented in July 2007, data about its effects are still scarce. The reform caused TFR flows amounting to 3.2 billion euro to be invested in pension funds during 2007, which is 1.5 billion more than in 2006 (Covip, 2008a). About 30\% of private sector employees were members of a pension fund in 2007, compared to about $25 \%$ in 2006 (Covip, 2008b).

A broader view on the reform is provided by an ad hoc survey carried out by Eurisko for Anima Research Lab on more than 1,000 private sector employees who were asked how they allocated their TFR flows (the data are described in greater detail in Boeri and Zingales, 2008). Table 1 reports some summary statistics about workers' choices as of July 1st 2007, and allows to infer the actual destination of TFR flows.

${ }^{12}$ The aggregate flows accruing each year are calculated as

$$
\text { FlowTFR } R_{i, t}=6,91 \% * W_{t f r(i, t)}
$$

where $W_{t f r(i, t)}$ is the aggregate gross wage received by employees.

${ }^{13}$ The TFR stock at the end of each year is equal to:

$$
T F R_{i, t}=\left(1+r_{t}\right)\left(T F R_{i, t-1}-T F R L I Q_{i, t}\right)+F l o w T F R_{i, t}
$$

where $T F R L I Q_{i, t}$ is the amount of TFR liquidated in year $t$ due to the exit of the employee from the firm, and $r_{t}$ is the rate at which TFR is capitalized annually, that is $1.5 \%$ plus $3 / 4$ of the inflation rate annually measured by ISTAT.

${ }^{14}$ That is medium and large firms according to the European classification (EC, 2003). 
Table 1: Workers' choice and TFR destination, by firm size (percentages)

\begin{tabular}{lrrr}
\hline \hline "Raw" private employees' choices & & & \\
& $<50$ & $50+$ & Total \\
\cline { 2 - 4 } Pension Fund & 10.09 & 41.48 & 22.65 \\
Firm & 77.50 & 47.67 & 65.57 \\
Did not choose & 12.4 & 10.85 & 11.78 \\
Total & 100.0 & 100.0 & 100.0
\end{tabular}

\section{TFR destinations}

Pension Fund

\begin{tabular}{rrr}
$<50$ & $50+$ & Total \\
\hline 22.49 & 52.33 & 34.43 \\
77.50 & 0.00 & 46.51 \\
0.00 & 47.67 & 19.06 \\
100.0 & 100.0 & 100.0 \\
\hline
\end{tabular}

Firm

INPS

Total

Source: own elaboration on FRBD, 2008.

Note: percentages in the bottom panel are computed recalling that not choosing is equivalent to putting the TFR into pension funds, and that in firms with 50+ employees TFR flows not going to pension funds are diverted to INPS. All data weighted using FRDB (2008) weights.

Table 1 shows workers' choices about their TFR (first panel) and how these choices translated in terms of TFR allocation (second panel). The most preferred choice - both in small and medium-large firms - is to leave the funds at the employer's disposal. Analogously, the percentage of workers who do not choose any specific investment for their TFR is quite similar across firm size. However, a remarkable difference between the two groups is given by those who actively decided: only $10 \%$ out of small firms' workers decided to join a pension fund, while this percentage increases to 41.5 in larger firms. Using other answers from the same survey, Boeri and Zingales (2008) suggest that workers trust more their own firm than INPS, so when faced with the choice between pension funds and INPS they tend to choose the former more often than when they have to decide between pension funds and firm ${ }^{15}$.

\footnotetext{
${ }^{15}$ This happens even though TFR flows into INPS are going to receive exactly the same treatment as within the firm in terms of capitalization and workers are not going to
} 
The idea that workers in firms with $50+$ employees chose pension funds more often than workers in smaller ones is confirmed by Covip data on the participation to occupational funds: the membership rate of private sector employees is $12 \%$ in firms with less than 50 workers and $42 \%$ in medium-large ones (Covip, 2008a).

In order to get an insight on the outflows of TFR from Italian SMEs, we first focus on the forecasts of the total yearly TFR, which represent the (maximum) total amount of money that can be diverted from firms due to the reform ${ }^{16}$. Table 2 shows TFR flows in 2007, by firm size. Various Istat sources have been employed to assess the magnitude of $2007 \mathrm{TFR}^{17}$. As Table 2 shows, small firms make up for more than half private sector employees. However, since earnings are on average higher in larger firms most TFR is accumulated in firms with more than 50 employees.

Table 2: Macro data on earnings and TFR, 2007

\begin{tabular}{|c|c|c|c|c|}
\hline & $\begin{array}{r}\text { Private sector } \\
\text { employees } \\
\text { (number) } \\
\end{array}$ & $\begin{array}{r}\text { Avg gross earnings } \\
\text { per employee } \\
\text { (Th euro) }\end{array}$ & $\begin{array}{l}\text { Wage bill } \\
\text { (Th euro) } \\
\end{array}$ & $\begin{array}{l}\text { Total TFR } \\
\text { (Th euro) } \\
\end{array}$ \\
\hline$<50$ & $6,014,429$ & 18.737 & $112,691,294$ & $7,786,968$ \\
\hline $50+$ & $5,662,249$ & 26.950 & $152,597,242$ & $10,544,469$ \\
\hline Total & $11,676,678$ & 22.528 & $265,288,537$ & $18,331,438$ \\
\hline
\end{tabular}

Source: Istat, various years

experience any practical difference.

${ }^{16}$ In doing this, we assume that the reform is not affecting the labor market conditions, i.e. is not going to provoke a change in the structure of employment (between SMEs and large firms) nor is going to affect the duration of employment. Also, we do not try to estimate the outflows of TFR due to workers changing employer or leaving the labor market, which in reality affect the availability of funds for each firm (Fugazza and Teppa, 2005). Our approach to the labor market conditions is admittedly strong, since it reduces to an estimate of future inflows to the TFR based only on the total employment level and the average remuneration.

${ }^{17}$ The number of private sector employees up to 2006, by firm size, is from ISTAT (2008). The 2007 figure has been obtained applying the growth rate of dependent employees as from ISTAT, (2008). The average gross earnings per dependent employee, by firm size, up to 2005 comes from ISTAT (2007). Growth rates up to 2007 are from ISTAT (2008). The wage bill has been obtained by multiplying the number of dependent employees by their average salary. Total TFR corresponds to $6.91 \%$ of the wage bill. 
The amount of TFR amount shown in Table 2 is then used to compute TFR destinations in 2007, applying the participation rates to the reform reported in Table 1, and assuming that all choices concerning TFR destination were taken as of July 1st 2007. We compute the total amount of TFR flows that were respectively invested into pension funds, collected by INPS, or remained within the firms in 2007. The results of Table 3 include how much TFR has been "lost" by firms, that is the sum of TFR paid to INPS and to pension funds ${ }^{18}$.

A few remarks are needed regarding the results of Table 3. First, the flow to pension funds and INPS in 2007 is relatively small because the reform does not apply to the whole year. Therefore, firms will "lose" relatively more funds in the future. Second, most TFR is lost by medium-large firms both because they accumulate most TFR and because they lose this source of financing entirely (either to INPS or to pension funds). On the contrary SMEs $(<50)$ lose a smaller amount (i.e. only the flows diverted to pension funds).

Although results in Table 3 are obtained under admittedly strong assumptions, they are closely in line with aggregate data from other sources. First, Covip (2008a) reports that the amount of TFR flows conveyed in pension funds in 2007 was equal to 3.2 billion euro. The fact the we obtain a slightly higher value might be because some workers are allowed to invest in pension funds only a fraction of their TFR. Second, according to ISTAT (2008) the total amount of TFR lost by firms in 2007 amounted to 6.8 billion euro and the TFR flows going into firms ${ }^{19}$ were about 13.9 billion in the same year. Both figures are not too distant from what we find (respectively 6.1 and 12.2 billion euro).

Table 4 shows projections of TFR flows that firms are going to "lose" in the future, according to various hypotheses about macroeconomic scenarios and the participation to the reform. We chose three growth rates for the total TFR $(2.5 \%, 3.5 \%, 4.5 \%)$ reflecting employment and wages growth ${ }^{20}$ and two alternative scenarios for workers' participation in pension funds. In the first we assumed workers are going to choose their future TFR destination with the same frequencies as of July 2007. In the second, we assume an increasing participation to private pension funds $(50 \%$ of TFR in pension funds by 2010).

\footnotetext{
${ }^{18}$ We assume that workers' choices about TFR destination - as displayed in the second panel of Table 1 - only apply to TFR flows in the second semester.

${ }^{19}$ We have adjusted the figures in order to make them comparable with those of Table 2 , by subtracting agricultural/fishery in accordance with the definition used in ISTAT, (2008).

${ }^{20}$ Overall TFR grew at an average rate of $3.6 \%$ in the $2000-2006$ period (ISTAT, 2008)
} 
Table 3: TFR destination, by firm size (Th euro)

\begin{tabular}{lrrr}
\hline \hline & \multicolumn{2}{r}{$50+$} & Total \\
\cline { 2 - 4 } Second semester 2007 & & & \\
Pension funds & 875,645 & $2,758,960$ & $3,634,605$ \\
Firm & - & - & $3,017,450$ \\
INPS & $3,893,484$ & $5,272,234$ & $2,513,274$ \\
Total & & & $9,165,719$ \\
& & \\
Total 2007 & 875,645 & $2,758,960$ & $3,634,605$ \\
Pension funds & $6,910,934$ & $5,272,235$ & $12,183,169$ \\
Firm & - & $2,513,274$ & $2,513,274$ \\
INPS & $7,786,968$ & $10,544,469$ & $18,331,438$ \\
Total & & \\
& 875,645 & $5,272,235$ & $6,147,879$ \\
Total TFR "lost" by firms & & \\
\hline \hline
\end{tabular}

Source: own elaboration on Istat (various years) and FRDB (2008).

Note: To compute data in this table we use TFR amounts from the last column of Table 2 - halved to reflect our assumption that choices are made as of July 1st 2007 - and apply to them the percentages indicated in the second panel of Table 1, indicating TFR destinations. TFR "lost" by firms equals the sum of TFR paid to pension funds and INPS.

As we can see, TFR lost from 2008 on roughly doubles with respect to 2007 and - as already noted - every year medium-large firms lose a remarkably higher amount than small ones (which lose up to 4.4 billion euro in 2010) with respect to the case of no reform. Moreover, the amount of TFR lost by firms is obviously increasing with higher TFR growth rates and in the scenario where workers' participation to pension funds increases.

In the following, we derive some first indications on the potential impact of TFR outflows on the loan rate paid by firms.

The main theoretical predictions of the model are contained in equations (8) and (9). Thus, we will calibrate the main parameters of the model on real data.

The bank's participation constraint reads as: $I^{b}=E\left(R^{b}\right) I / \beta$, that is $E\left(R^{b}\right)=\beta I^{b} / I$. We measure $I^{b} / I$ with the ratio between financial debt over total capital observed on the capital structure of firms. The reason for our choice is the following: if we assume that the optimal capital structure is 
quite stable across time, the leverage ratio we observe should correspond to the optimal ratio between the flow of external finance and the total capital flow. Guiso (2003) measures this ratio for Italian manufacturing firms from a survey of over 4,000 firms (mostly small and medium-sized) conducted in 1999 by Mediocredito Centrale, obtaining a median value of $23.1 \%$ and an average value of $32.2 \%$. We use these two statistics as an estimate of $I^{b} / I$.

Furthermore, we obtain a measure of the total bank credit to firms from the "Bollettino Statistico" of the Bank of Italy: in this report, we can observe the total credit granted from banks (and other financial institutions) to all clients, classified by loan size. We obtain from this document, for each class, both the number of credits and the total amount lent by all banks and financial institutions in Italy. We use this information to estimate the total capital $K_{b}^{*}$ banks lend to firms at equilibrium before the reform. Reasonably, small firms obtain on average credits of relatively small amounts, hence we refer to the credit classes with less than 250,000 euros. Since SMEs are probably not the only clients obtaining such a loan (households mortgages for investments in real estate represent for sure an important quota of these loans), we consider the numbers reported by Bank of Italy as an upper bound of the credits granted to SMEs.

To compute the impact of the reform on the loan rate paid by SMEs who still have access to bank credit pre- and post-reform, we need the equilibrium loan rate pre-reform, and the elasticity of the banks supply of capital to the loan rate. We obtain information about the average loan rate currently paid by SMEs from the survey by Capitalia (2005), indicating an average rate of $7.4 \%$ for the period 2001-2003 across all size classes. We use the lower and the upper bounds $(5.4 \%$ and $8.2 \%)$ in this same survey as two limit scenarios.

Finally, to estimate the elasticity of the loan supply with respect to the loan rate we rely on Huelsewig, Mayer and Wollmershaeuser (2005) who use aggregate data to estimate the response of bank loans to a monetary policy shock. As a robustness check, we also use the estimates in King (1986), and we notice that the sensitivity of the change in the loan rate to this elasticity parameter is extremely low. Finally, the impact of the reform on the future investment is independent of this parameter (see equation (9)). Our main conclusions are collected in Table 5 .

Table 5 indicates that the impact of the outflow of TFR from the balance sheet of SMEs on the loan rate is, in any of the scenarios, negligible (a maximum reduction of far less than one basis point in any possible scenario). Indeed, the model forecasts that the reduced amount of assets forces some firms to lose their access to credit, reducing the aggregate demand of loans that banks can accept. The impact on the loan rate is proportional to the outflow of TFR, but in any case we see that this amount is too low to produce 
any important macroeconomic effect on $\beta$.

However, according to (9) and (5), the reform will produce an important reduction of SMEs investment. In particular, the forecasted reduction is more than proportional to the outflow of the TFR, and it is larger the larger the quota of investment actually financed by the banks (i.e. the higher the leverage ratio of SMEs, according to our assumptions). We assess that this reduction can be about $130 \%-147 \%$ of the future outflow of TFR, as an effect of the "multiplier" $1 /\left(1-I^{b} / I\right)$. To obtain this result we proxy $I^{b} / I$ with the amount of bank financing on total firms assets estimated by Guiso (2003) for Italian SMEs. The lower and the upper bounds of our interval correspond respectively to Guiso's highest and lowest estimates of the ratio between bank financement and total firm assets.

We conclude then that if the reform will have a negative impact on the SMEs, this will be due to their reduced access to bank credit, and not to more expensive loans for those firms who will continue to access bank credit. Some of the SMEs will be forced to ask more financing, and due to the risk of moral hazard, banks will reject their requests; this in turn will decrease aggregate investment. A useful policy intervention would then subsidize the access to credit for firms. Just subsidizing loans that are in any case already granted by banks to some of the SMEs, as the government decided to do in the 2007 law, is not going to reduce the inefficiency.

\section{Conclusions}

The lack of external capital is often quoted as one of the main impediments for SMEs to grow. In the presence of a moral hazard problem between the borrowing firm and external financiers, the debt capacity of the former depends on the amount of collateral SMEs can pledge to the lender (Berger and Udell (1995), Holmstrom and Tirole (1997)), and the amount of liquid assets they invest in the new projects. In our paper, we study the effects of the 2007 government reform of the system of severance indemnities currently in use for Italian employees on the cost and the access to credit for Italian SMEs. The most direct consequence of the reform is to reduce the amount of liquid assets of Italian firms, with respect to the situation pre-reform. Some empirical literature (Guiso (2003), Bianco (1997), Sapienza (1997)) provides evidence that Italian firms are credit constrained if they operate below a certain assets threshold, suggesting that the liquid net worth is one of the main determinants for their debt capacity. The Italian severance payments reform produces then a structural break on the dynamics of SMEs liquid assets which fully satisfies the assumptions of the debt capacity theory 
mentioned above. We use the model of Holmstrom and Tirole (1997) to make predictions about the effects of such a reform on the aggregate investments of SMEs, their access to credit, and the loan rate.

In order to gain insight on the reform effects, we performed an estimate of the future outflows from the severance indemnities fund. As the reform reaches its steady-state from 2008 on, the overall annual outflow amounts to over 10 billion euro. However, most of the outflow affects medium-large firms, while SMEs suffer a relatively smaller loss.

Using the annual outflows computed under different scenarios, we then provided some estimates of the effects on the loan rate and investments according to our theoretical model. First, the impact of the outflow of TFR from the balance sheet of SMEs on the cost of intermediated finance is likely to be, in any of the scenarios, negligible. Indeed, the model forecasts that the reduced amount of assets forces some firms to lose their access to credit, reducing the aggregate demand of loans that banks can accept, but this amount is too low to produce any important macroeconomic effect on $\beta$. Second, we showed that the proposed reform will reduce in the long run the aggregate investment by SMEs at a rate that is more than proportional to the outflows of TFR funds: this reduction is higher the higher the current leverage ratio of firms.

\section{References}

Bardazzi, R. and M. G. Pazienza, (2006), "La riforma del TFR e il costo per le imprese minori: un'analisi di microsimulazione", Politica Economica 22, nr. 1, 5-50.

Berger, A. N. and G. F. Udell (1998), "The economics of Small Business finance: The roles of private equity and debt markets in the financial growth cycle", Journal of Banking and Finance 22, 613-673.

Bianco, M. (1997), "Vincoli finanziari e scelte reali delle imprese italiane: gli effetti di una relazione stabile con una banca", in Le banche e il finanziamento delle imprese, a cura di I. Angeloni, V. Conti and F. Passacantando, Ente per gli Studi Monetari e Finanziari "Luigi Einaudi", pp. 33-60, Rome.

Boeri Tito and Luigi Zingales, (2008), "Chi ha paura dei fondi pensione?", Anima FinLab, Numero 12008

(https://www.animasgr.it/ANIMA/IT/AnimaFinLab/)

Broecker, T. (1990) "Credit-Worthiness and Interbank Competition", Econometrica 58, no. 2, 429-452.

Capitalia (2005), "Indagine sulle imprese italiane - Rapporto sul sistema produttivo e sulla politica industriale", Osservatorio sulle piccole e medie 
imprese, Ottobre 2005.

Carletti, E., V. Cerasi and S. Daltung (2005), "Multiple-bank lending: diversification and free-riding in monitoring", Mimeo, Center for Financial Studies University of Frankfurt.

Carletti, E. (2004), "The Structure of Relationship Lending, Endogenous Monitoring and Loan Rates", Journal of Financial Intermediation 13, pp.5886.

Chiesa, G. (2001), "Incentive-Based Lending Capacity, Competition and Regulation in Banking", Journal of Financial Intermediation 10, pp. 28-53.

Covip (2008a), "Relazione per l'anno 2007", Covip, Roma.

Covip (2008b), "La previdenza complementare nel 2007. Dati provvisori", Covip, Roma.

Detragiache, E., P. Garella and L. Guiso (2000), "Multiple vs. Single Banking Relationship: Theory and Evidence", Journal of Finance 55, p..1133-1161.

Diamond, D. (1984), "Financial Intermediation and Delegated Monitoring", Review of Economic Studies 51, pp. 393-414.

European Commission, (2003), "Commission Recommendation of 6 May 2003 concerning the definition of micro, small and medium-sized enterprises (2003/361/EC)", Official Journal of the European Union 20.5.2003, Brussels.

Freixas, X. and J.C. Rochet (1998) "Microeconomics of Banking" MIT Press.

Fugazza C., and F. Teppa (2005), "An Empirical Assessment of the Italian Severance Payment", WP CeRP No 38/05.

Garibaldi, P. and L. Pacelli (2004), "Do Larger Severance Payments Increase Individual Job Duration?," CEPR Discussion Papers 4607.

Guiso, L. (2003), "Small business finance in Italy", EIB Papers Vol. 7 no. 2 .

Holmstrom, B. and J. Tirole (1997), "Financial Intermediation, Loanable Funds, and The Real Sector", Quarterly Journal of Economics 112, no. 3, pp. 663-691.

Huelsewig, O., E. Mayer and T. Wollmershaeuser (2005), "Bank Loan Supply and Monetary Policy Transmission in Germany: an assessment based on matching impulses responses", CESInfo WP no. 1380, University of Munich.

King, S. (1986), ""Monetary Transmission: Through Bank Loans or Bank Liabilities?", Journal of Money, Credit and Banking, Vol. 18, no. 3, pp. 290303.

Istat, (2008), "Conti Economici Nazionali, 1970-2007", available online.

Istituto di Studi e Analisi Economica, (2005), "Rapporto ISAE, Finanza pubblica e redistribuzione", Ottobre 2005, Rome. 
Palermo, G. and M. Valentini (2000) "Il Fondo di Trattamento di Fine Rapporto e la struttura finanziaria delle imprese manifatturiere", WP n. 12 02/2000 Banca di Roma.

Pammolli, F. and N. C. Salerno (2006) "Le imprese e il finanziamento del pilastro previdenziale privato" Nota CERM 02/2006.

Petersen, M. and R. Rajan (1994), "The Benefit of Lending Relationships: Evidence from Small Business Data", Journal of Finance 49, pp. 1367-1400.

Petersen, M. and R. Rajan (1995), "The Effect of Credit Market Competition on Lending Relationships", Quarterly Journal of Economics 110, pp. 407-443.

Rajan, R. (1992), "Insiders and Outsiders: The Choice between Informed and Arm's-Lenght Debt", Journal of Finance 47, pp. 1367-1400.

Sapienza, P. (1997) "Le scelte di finanziamento delle imprese italiane", in Le banche e il finanziamento delle imprese, a cura di I. Angeloni, V. Conti and F. Passacantando, Ente per gli Studi Monetari e Finanziari "Luigi Einaudi", pp. 61-94, Rome. 
Table 4: TFR projection 2007-2010, by destination (billion euro)

\begin{tabular}{|c|c|c|c|c|c|c|c|c|}
\hline \multirow[b]{2}{*}{ TFR growth: $2.5 \%$} & \multicolumn{4}{|c|}{ Same choices as in 2007} & \multicolumn{4}{|c|}{ Increasing participation to $\mathrm{PF}$} \\
\hline & 2007 & 2008 & 2009 & 2010 & 2007 & 2008 & 2009 & 2010 \\
\hline Pension funds & 3.6 & 7.5 & 7.6 & 7.8 & 3.6 & 9.0 & 10.8 & 12.7 \\
\hline Firm & 12.2 & 6.2 & 6.3 & 6.5 & 12.2 & 5.5 & 4.8 & 4.2 \\
\hline INPS & 2.5 & 5.2 & 5.3 & 5.4 & 2.5 & 4.3 & 3.6 & 2.8 \\
\hline Total & 18.3 & 18.8 & 19.3 & 19.7 & 18.3 & 18.8 & 19.3 & 19.7 \\
\hline Lost by firms, of which & 6.1 & 12.6 & 12.9 & 13.2 & 6.1 & 13.3 & 14.4 & 15.5 \\
\hline$<50$ & 0.9 & 1.8 & 1.8 & 1.9 & 0.9 & 2.5 & 3.3 & 4.2 \\
\hline $50+$ & 5.3 & 10.8 & 11.1 & 11.4 & 5.3 & 10.8 & 11.1 & 11.4 \\
\hline TFR growth: $3.5 \%$ & 2007 & 2008 & 2009 & 2010 & 2007 & 2008 & 2009 & 2010 \\
\hline Pension funds & 3.6 & 7.5 & 7.8 & 8.1 & 3.6 & 9.1 & 11.0 & 13.1 \\
\hline Firm & 12.2 & 6.2 & 6.5 & 6.7 & 12.2 & 5.5 & 4.9 & 4.3 \\
\hline INPS & 2.5 & 5.2 & 5.4 & 5.6 & 2.5 & 4.4 & 3.7 & 2.9 \\
\hline Total & 18.3 & 19.0 & 19.6 & 20.3 & 18.3 & 19.0 & 19.6 & 20.3 \\
\hline Lost by firms, of which & 6.1 & 12.7 & 13.2 & 13.6 & 6.1 & 13.5 & 14.7 & 16.0 \\
\hline$<50$ & 0.9 & 1.8 & 1.9 & 1.9 & 0.9 & 2.6 & 3.4 & 4.3 \\
\hline $50+$ & 5.3 & 10.9 & 11.3 & 11.7 & 5.3 & 10.9 & 11.3 & 11.7 \\
\hline TFR growth: $4.5 \%$ & 2007 & 2008 & 2009 & 2010 & 2007 & 2008 & 2009 & 2010 \\
\hline Pension funds & 3.6 & 7.6 & 7.9 & 8.3 & 3.6 & 9.2 & 11.2 & 13.5 \\
\hline Firm & 12.2 & 6.3 & 6.6 & 6.9 & 12.2 & 5.6 & 5.0 & 4.4 \\
\hline INPS & 2.5 & 5.3 & 5.5 & 5.7 & 2.5 & 4.4 & 3.7 & 3.0 \\
\hline Total & 18.3 & 19.2 & 20.0 & 20.9 & 18.3 & 19.2 & 20.0 & 20.9 \\
\hline Lost by firms, of which & 6.1 & 12.8 & 13.4 & 14.0 & 6.1 & 13.6 & 15.0 & 16.5 \\
\hline$<50$ & 0.9 & 1.8 & 1.9 & 2.0 & 0.9 & 2.6 & 3.5 & $4 \cdot 4$ \\
\hline $50+$ & 5.3 & 11.0 & 11.5 & 12.0 & 5.3 & 11.0 & 11.5 & 12.0 \\
\hline
\end{tabular}

Note: 2007 amounts are taken from Table 3 and are then projected according to a TFR growth hypothesis $(2.5 \%, 3.5 \%, 4.5 \%)$ and a participation hypothesis. In the scenario "Same choices as in 2007" we assumed workers will choose their TFR destination with the same frequencies as in 2007. In the scenario "Increasing participation to PF", we assume that $50 \%$ of TFR will be paid to pension 2010 . 
Table 5: Decrease in the loan rate (percentage points) due to the reform

\begin{tabular}{cccrrrr}
\hline \hline $\begin{array}{c}\text { Bank } \\
\text { financing }^{a}\end{array}$ & $\begin{array}{c}\text { Interest } \\
\text { rate }^{b}\end{array}$ & $\begin{array}{c}\text { Loans supply } \\
\text { elasticity }\end{array}$ & \multicolumn{2}{c}{ "Same as 2007" } & \multicolumn{2}{c}{ "Increased particip." } \\
\hline 23.1 & 5.4 & 0.14 & 0.000090 & 0.000091 & 0.000127 & 0.000128 \\
& & 0.65 & 0.000066 & 0.000067 & 0.000093 & 0.000094 \\
\cline { 2 - 6 } & 8.2 & 0.14 & 0.000137 & 0.000138 & 0.000192 & 0.000194 \\
& & 0.65 & 0.000101 & 0.000102 & 0.000142 & 0.000143 \\
\hline 32.2 & 5.4 & 0.14 & 0.000127 & 0.000128 & 0.000178 & 0.000180 \\
& & 0.65 & 0.000096 & 0.000097 & 0.000136 & 0.000137 \\
\cline { 2 - 6 } & 8.2 & 0.14 & 0.000193 & 0.000194 & 0.000271 & 0.000274 \\
& & 0.65 & 0.000146 & 0.000148 & 0.000206 & 0.000208 \\
\hline \hline
\end{tabular}

Sources:

${ }^{a}$ Guiso (2003)

${ }^{b}$ Lower and upper bounds from Capitalia (2003)

${ }^{c}$ Huelsewig, Mayer and Wollmershaeuser (2005); King (1986)

Note: by rearranging equation (8) we obtain $\frac{d \beta}{d K_{f}}=\frac{\beta \frac{I^{b}}{I}}{K_{b}^{*}\left(1+\frac{K_{b}^{*}}{K_{b}^{*}} \beta\left(1-\frac{I^{b}}{T}\right)\right)}$ where $\frac{I^{b}}{I}$ is "Bank

financing", $\beta$ is "Interest rate", and $\frac{K_{b}^{\prime}}{K_{b}^{*}} \beta$ is the "Loans supply elasticity". The "Same as 2007" and "Increased participation" scenarios are those of Table 4. 